\title{
ANIMAL MODELS OF OSTEOPOROSIS - NECESSITY AND LIMITATIONS
}

\author{
A. Simon Turner* \\ Department of Clinical Sciences, Colorado State University, Ft. Collins, CO 80523, USA.
}

\begin{abstract}
There is a great need to further characterise the available animal models for postmenopausal osteoporosis, for the understanding of the pathogenesis of the disease, investigation of new therapies (e.g. selective estrogen receptor modulators (SERMs)) and evaluation of prosthetic devices in osteoporotic bone. Animal models that have been used in the past include non-human primates, dogs, cats, rodents, rabbits, guinea pigs and minipigs, all of which have advantages and disadvantages. Sheep are a promising model for various reasons: they are docile, easy to handle and house, relatively inexpensive, available in large numbers, spontaneously ovulate, and the sheep's bones are large enough to evaluate orthopaedic implants. Most animal models have used females and osteoporosis in the male has been largely ignored. Recently, interest in development of appropriate prosthetic devices which would stimulate osseointegration into osteoporotic, appendicular, axial and mandibular bone has intensified. Augmentation of osteopenic lumbar vertebrae with bioactive ceramics (vertebroplasty) is another area that will require testing in the appropriate animal model. Using experimental animal models for the study of these different facets of osteoporosis minimizes some of the difficulties associated with studying the disease in humans, namely time and behavioral variability among test subjects. New experimental drug therapies and orthopaedic implants can potentially be tested on large numbers of animals subjected to a level of experimental control impossible in human clinical research.
\end{abstract}

Key Words: Osteoporosis, osteopenia, animal models, bone mineral density, ovariectomized sheep, bone metabolism, hormonal therapy, selective estrogen receptor modulatorss, implants, ceramics, vertebroplasty.

*Address for correspondence

A. Simon Turner

Department of Clinical Sciences

Colorado State University

Ft. Collins

CO 80523

USA

E-mail: sturner@lamar.colostate.edu

Telephone Number: 970-491-0379

Fax Number: 970-491-0303

\section{Review of Animal Models of Osteoporosis}

\section{General introduction to the need for animal models}

Postmenopausal osteoporosis is a major health problem for women, the understanding of which is hindered by the difficulty of studying a disease that is restricted to humans. Osteoporosis is a slowly progressive disease, necessitating a study of several years' duration to allow for a response to therapy. Because results come slowly, accumulation of data is time consuming, and maintenance of a study group is made more difficult by natural attrition due to either relocation or death.

Lifestyle and health-related factors such as smoking, alcoholism, and diet have been linked with an increased incidence of the osteoporosis (Heaney, 1996; Seeman 1996). This presents a difficulty when trying to create a homogeneous study group, since so many elements can influence results. A consequence of this disparity is data affected by relatively high variance.

Fall-related injuries pose the most serious health risks associated with the disease, causing prolonged hospital stays, greater mortality rates, and at the very least an increased dependence on people or devices for mobility (Grisso et al., 1997). With such injuries, not only cost, but also quality of life is a serious consideration for individuals with osteoporosis. While the best defense against the disease is prevention, there is also a great need for treatment of those with established osteoporosis and related conditions.

Animal models provide more uniform experimental material and allow for extensive testing of potential therapies. A carefully chosen, appropriate experimental animal model for the study of osteoporosis minimizes the limitations associated with studying the disease in humans, namely time and behavioral variability among test subjects. Since 1994, the US Food and Drug Administration (FDA) requires data from both the rat and a well-validated large animal model for preclinical evaluation of new experimental drug therapies at a clinical dose and 5 times the dose. The high cost and long time frame of clinical testing are other reasons why animal models play a crucial role in osteoporosis research (Hartke, 1999). Even a model with a small representation of human functions may be of use for some aspect of the human condition under examination (Hazzard et al, 1992).

An additional goal for research into osteoporosis is the design of prosthetic devices (with or without biological coatings to promote osseointegration) that will perform optimally in the presence of osteoporotic bone. The biological and biomechanical characteristics of orthopaedic implants, bone-graft substitutes (with or without osteogenic bone morphogenetic proteins) can be tested on large 
numbers of animals maintained with a level of experimental control, impossible in human clinical research (Newman et al., 1995).

\section{Requirements for an ideal animal model}

Selection of a suitable animal model is difficult. Many factors must be considered when discussing possible models for osteoporosis, and these are well defined by Rodgers et al. (1993) as "convenience, relevance (comparability to the human condition), and appropriateness: a complex of other factors that make a given species the best for studying a particular phenomenon".

An appropriate animal model for any research should be based on the following considerations: "1) appropriateness as an analog, 2) transferability of information, 3) genetic uniformity of organisms where applicable, 4) background knowledge of biological properties, 5) cost and availability, 6) generalizability of the results, 7) ease and adaptability to experimental manipulation, 8) ecological considerations, and 9) ethical and societal implications" (Davidson et al., 1987). When considering animal models for osteoporosis research we need to ask whether the disease is truly represented with the following questions: What is the age at peak bone mass? Is there age-dependent bone loss? Do we see estrogen-reversible bone loss (i.e. can bone loss be restored)? Do spontaneous fractures occur? Is the disease the same (e.g. increased fragility at relevant sites)? Is the magnitude of the disease the same? Are there changes in cortical bone as well cancellous bone? Are there confounding effects following ovariectomy (OVX) e.g. weight gain, increased appetite? Is one animal model enough? Should we consider models for different degrees of osteoporosis?.

It will be clear in this review that animal models used for the study of osteoporosis and related conditions meet some, but certainly not all of these considerations. For example, with regard to bone density and quality parameters of the lumbar spine, humans appear to be very different from dog, pig, cow, sheep, chicken and rat (Aerssens et al., 1998). Furthermore, when selecting animal models "a broadly generalizable body of knowledge cannot be generated from employment of any single model system. The field as a whole must exploit diverse models" (Hazzard et al., 1992). This paper will review several animal models to study osteopenia induced by ovariectomy (OVX) and related conditions, with emphasis on the author's experience with one of the most practical large-animal models, the aged OVX ewe. It is beyond the scope of this review to review the bone physiology of each animal model. The review will also discuss some models used to evaluate implants in osteopenic bone and augmentation of osteopenic vertebrae (vertebroplasty).

\section{Primates (non-human)}

An abundance of literature documents the skeletal effects of ovariectomy in old-world monkeys such as baboons and macaques (rhesus and cynomolgus) as well as the use of different therapies to meet certain regulatory requirements. These non-human primates demonstrate many advantages over other models for osteoporosis as their organ systems most closely resemble the human systems involved, i.e. gastrointestinal tract, endocrine system, and bone metabolism. For example, female macaque monkeys cycle monthly and have hormonal patterns similar to those of the human (Hodgen et al., 1977). Most studies in primates have focused on the loss of trabecular bone, and cortical sites have not been examined as extensively. A significant reduction in vertebral cancellous bone volume occurs in response to ovariectomy of the female monkey (Miller et al., 1986) while gonadotropin releasing hormone agonist-treated female rhesus monkeys exhibit decreased bone mineral density at a rate of loss comparable to the human postmenopausal woman (Mann et al., 1990). These data show a similarity between non-human primates and the human in the response of bone to cessation of ovarian function.

Menopause occurs in female primates after approximately 20 years of age (Kimmel, 1996). Both in captivity and in the wild, the live birth rate of primates declines markedly with age, with oligomenorrhea apparent early-to midtwenties. They are considered menopausal in the late twenties. Hormonal changes such as increased follicular stimulating hormone $(\mathrm{FSH})$ and decreased estrogen levels are also noted in monkeys $>20$ years of age.

As postmenopausal osteoporosis is clearly hormonerelated, the similarity in the endocrine system of the primate to that of the human is a notable advantage. Unfortunately, peak bone mass is not reached in cynomolgus monkeys until 9 years of age (Jayo et al., 1994), and most studies have used OVX monkeys aged 4-7 years (Jerome et al., 1993). Intuitively, OVX in the skeletally immature primate is an inappropriate model for postmenopausal osteoporosis. However, the acquisition of aged female primates is difficult and very costly.

The effect of OVX on quality and quantity of cancellous bone using the young cynomolgus monkey was evaluated after a 2-year period (Lundon et al., 1994). The bodies of the second lumbar vertebrae were analyzed for changes in bone mineral quality using density fractionation, chemical analysis, and X-ray diffraction techniques. It was concluded from this study that young, OVX female cynomolgus macaques do not appear to be a useful model for the study of postmenopausal bone loss, although they may be a useful animal model to evaluate skeletal pathology which might be observed after surgical ovariectomy in young human females (Lundon et al., 1994).

Biochemical markers of bone turnover have been studied in primates. OVX cynomolgus monkeys had increased serum levels of alkaline phosphatase and acid phosphatase compared with intact and hormone-supplemented animals (Jerome et al., 1994).

Once primates have been acquired for study, their handling becomes an issue of concern. While the sometimes aggressive primate can be sufficiently controlled by a skilled technician, the risk of zoonotic disease transmission from the animals is relatively high. Frequently, primates used for studies are not bred for research but are caught in the wild and are therefore potential reservoirs for a host of zoonotic diseases including the primate retroviruses, which have had a history of jumping host species (Newman et al., 1995; Weiss, 1998), a consideration which discourages the use of this animal as an experimental model. Other factors when using non-human primates are legislated housing and environmental stipulations for the animals, which 
creates public distaste for their use. Unfortunately, primates are too dangerous, costly, and difficult to handle for them to be a primary model for the study of therapeutic agents for osteoporosis. Rather, they are of most value as the final step toward clinical trials after a rat and a larger animal have been used.

\section{Dogs}

For many years, dogs have been a useful model for the human skeleton because of their extensive basic multicellular unit (BMU)-based remodeling. A review of the dog as a model for estrogen-depletion bone loss is available (Kimmel, 1991). Dogs are less expensive than the primate, easier to work with, and like the human, they are monogastric.

In a longitudinal study in beagles using densitometry as an endpoint Drezner and Nesbitt (1990) found an 8-10\% reduction in vertebral bone density 8 and 12 months postovariectomy. Some studies (Boyce et al., 1990) but not all (Martin et al., 1987; Malluche et al., 1986; Faugere et al., 1990; Monier-Faugere et al., 1993, 1996) have shown insignificant bone loss in dogs after cessation of ovarian function.

The bisphosphonate YM175 was tested in the OVX calcium-restricted beagle. The BMD, strength and structure and turnover of bone was evaluated and it was concluded that although calcium restriction increased the sensitivity of bone to OVX in rats and minipigs, such sensitivity was not increased in OVX beagles. Furthermore, it was stated that "the contribution of OVX to the reduction in bone mass and strength at the organ level in the OVX beagle model was small" (Motoie et al., 1995).

Group size has been a frequent problem of many studies in dogs but cancellous bone loss may be detectable in studies with large group sizes or with tools of greater precision (Boyce et al., 1990).

The resistance of the canine skeleton to natural estrogen deficiency or artificial estrogen recession may be related to the infrequent estrus cycle (Yamaura et al., 1993). Unlike humans and the primate models which are polyestrus, dogs are diestrus, with ovulation occurring twice a year [i.e., spring and fall (Fox and Laird, 1970)]. Hormone levels remain constant until estrus at which time they spike. Despite extremely low levels of estrogen throughout most of the year, spontaneous fractures of the appendicular or axial skeleton in dogs are almost unheard of in veterinary practice. Removal of both ovaries and uterus does not appear to be sufficient to create significant bone loss. Furthermore, the histologic response of the dog to loss of ovarian function appears to be heterogeneous, possibly due to the variation in duration of the post-OVX period. The remodeling changes (activation) in cancellous and cortical bone are transient and brief in nature (stabilization within 5-12 months), without sizeable bone loss (Boyce et al., 1990; Kimmel, 1991). Furthermore, the alterations in skeletal remodeling do not appear sufficiently sustained to have a substantial impact on cancellous bone microstructure and strength. There are millions of dogs without ovaries and uterus, many of them quite old, with sedentary lifestyles, and no fracture rate comparable to that of postmenopausal women exists. Compression tests on trabecular bone samples from vertebral bodies and distal femoral regions were performed 12 months after ovariectomy in beagles (McCubbrey et al., 1993). There was a decrease in mechanical properties of the vertebrae but femoral properties were conserved.

Dogs have been used as the second species for regulatory safety studies to assess the long-term safety of boneactive agents (e.g. bisphosphonates) on bone quality (Boyce et al., 1996; Grynpas et al., 1994; Forwood et al., 1995; Peter et al., 1996).

A study of the effect of estrogen depletion and PTH stimulation on ovariohysterectomized dogs found no significant changes in bone (Shen et al., 1992). It was concluded that "The lack of sizeable responses in histomorphometric, bone mass and biochemical parameters may limit the utility of dogs for the study of cancellous bone loss in ovarian-dysfunction osteoporosis" (Shen et al., 1992).

Although dogs may be of limited use as a model for estrogen deficient-related bone loss, they have been extremely useful for evaluation of general aspects of the human skeleton (e.g., fracture healing, effects of immobilization, long-term effects of certain bone-active agents, allografts, etc.) as well as bone ingrowth and joint replacement (Stulberg et al., 1991; Bloebaum et al., 1993; Sumner et al., 1999; Harvey et al., 1999). In a study that compared bone composition, density and quality in bone samples derived from seven vertebrates that are commonly used in bone research: human, dog, pig, cow, sheep, chicken, and rat, large interspecies differences were observed. Of all species included in the biochemical analyses, rat bone was most different whereas canine bone best resembled human bone (Aerssens et al., 1998). It has been suggested that by controlling for important variables in dogs such as sex or ovarian function, and age, the more expensive primate animal model is not needed for experimentation on bone ingrowth (Shaw et al., 1994). However, these authors found that values for ingrowth were not significantly altered by the presence or absence of ovarian function, suggesting that lack of ovarian function does not appear to be a contraindication to the use of a porous ingrowth prosthesis. Cats

Osteopenia can be induced in growing cats through immobilization, by feeding a low calcium diet, or by feeding a high phosphorus diet. Bone disease occurs frequently in young cats fed an all-meat diet without calcium supplementation, yet they have adapted to both very low $\mathrm{Ca}: \mathrm{P}$ ratios and acidified diets (Draper, 1985). These findings as well as ease in handling and housing, would suggest that cats may be useful in the study of osteoporosis. One study used cats to investigate the effects of fluoride (Chavassieux, 1990).

Because cats are companion animal animals, public acceptance of cats in research will be an increasing problem. Furthermore, most pet female cats are ovariohysterectomized, yet spontaneous fractures are as rare in cats as in dogs; an observation that is a major deterrent against the use of this model.

\section{Rats and Mice}

The most commonly used animal model for osteoporosis studies is the rodent (Barlet et al., 1994) and this review will concentrate on the rat. The mouse is used for manipu- 
lation of the genome and this will not be discussed. The OVX rat exhibits most of the characteristics of human postmenopausal osteoporosis. With the fast generation time, rodents are often a starting point for preliminary screenings, efficacy and toxicity of a new pharmacological agents or therapeutic modality, followed by verification in other species, before undertaking clinical trials in human patients (Aerssens et al., 1998). Advantages of rodents are numerous; they are inexpensive, easy to house, and the general public is accustomed to the role of rodents for use in research. With intense interest in transgenic animals, availability of strains of mouse mutants with altered bone marrow function, availability of recombinent murine cytokines, mice will always be the logical staring point for manipulation of the genome (O'Brien et al., 1997). A SenescenceAccelerated Mouse (SAM) mouse has been developed as a model for age-related spontaneous osteopenia (Okamoto et al., 1995).

There is extensive literature studying the OVX rat including the histomorphometric changes, biochemical markers, methodology for bone densitometry and evaluation of bone fragility (Wronski et al., 1985, 1986; Wronski and Yen, 1991; Frost and Jee, 1992; Kalu, 1991; Dempster et al., 1995). Genetically specific strains can be acquired, thus removing some variability in studies. Their shorter life span enables studies on the effects of aging on the bone. Because the rodent has been used so extensively in research of all types, much is known about bone turnover and the effect of diet on this process. Cortical thinning and increased fragility are well documented in aging rat and mouse bone, but it is unclear if this results in increased fractures. Weight gain in OVX rats can result in an increase in bone mass with increase in mechanical loading, resulting in protection of OVX animals against age-related loss of bone strength (Peng et al., 1997). Therefore bone changes are seen as osteopenia rather than osteoporosis.

Rodents do not experience a natural menopause but OVX has become a time-honored method used to produce an artificial menopause (Wronski et al, 1985, 1986; Wronski and Yen, 1991; Frost and Jee, 1992; Kalu, 1991). Although aged rodents have Haversian systems and OVX results in a significant bone loss, the use of this model is hindered because young rats have a limited naturally occurring BMU-based remodeling. Nevertheless, older rats have lamellar bone (although most is "fine-fibered"), trabecular remodeling, and some secondary osteonal remodeling (Wronski and Yen, 1991; Frost and Jee, 1992; Kalu, 1991). As older animals more accurately reflect the target population for proposed osteoporosis therapy, the very aged-rat model (30-month old) is an even better choice as a costeffective animal model (Gaumet et al., 1996). The inability to restore bone following OVX in rats is similar to human bone (Abe et al., 1993). Hysterectomy does not impair the ability of estradiol to conserve bone in OVX rats. In other words, estrogen mediated induction of growth factors from uterine tissue does not play an essential role in mediating the bone-conserving actions of estrogen in the rat (Goulding et al., 1996)

Longitudinal bone growth increases transiently after OVX in long bones of rats, but this can be minimized by the use of aged rats (9-12 months old) or of skeletal sites where the longitudinal growth is greatly reduced (e.g. lumbar vertebrae) (Wronski and Yen, 1991). Male rats are unsuitable models for osteopenia studies because growth plates do not close in less than 30 months.

The rat is a poor animal to study the effect of OVX on cortical bone because of the lack of Haversian systems, while another limitation is the absence of impaired osteoblast function during the late stages of estrogen deficiency (Wronski and Yen, 1991). However, rats do show significant elevation of cortical porosity in response to immobilization (Sietsma, 1995). Glucocorticoid treatment of rats will not induce osteopenia unless they receive a low-calcium $\operatorname{diet}$ (Jee et al., 1972).

In a study designed to investigate the effects of estrogen alone or combined with norethindrone or norgestimate on bone density and compressive mechanical properties in an aged (11-month old) rat model, both interrupted progestin regimens had a better effect than estrogen alone on vertebral bone density (Vanin et al., 1995). The findings of this study showed an increased flexibility, unlike the brittleness seen in osteopenic women. The authors stated "the rat model may therefore not be appropriate for comparison of mechanical properties with the human"...but they also said that "bone mineral density in the aged rat model.... seems to follow the same pattern as the human in relation to estrogen deficiency and gonadal hormonal replacement" (Vanin et al., 1995). Others (Peng et al., 1994) have found that the mechanical strength of the femoral neck was a sensitive indicator of bone loss associated with OVX, orchidectomy and immobilization.

Non-invasive measurement of bone mineral content (BMC) and bone mineral density (BMD) in rodents (while under general anesthesia) is now possible using DXA with ultra-high resolution software. However for very small animals $(<50 \mathrm{~g}$.), poor edge detection and accuracy limit the use of DXA (Grier et al., 1996). To improve resolution in smaller animals, microcomputed tomography (micro-CT), which can provide images of individual trabeculae similar to a histomorphometry slide, has become the industry standard. Micro-CT can image $20 \mu$ isotropic voxels and reconstruct a three-dimensional data set of bone, measuring connectivity, thereby determining the relationship between architecture and strength (Hartke, 1998).

As previously mentioned, a stipulation for a model to evaluate implants in osteopenic bone involves suitability for the testing of various prosthetic devices for say total hip arthroplasty. Clearly, the size of the rodent while advantageous for housing, is too small to be suitable for such procedures. However, rats are ideal models to evaluate smaller implants, various matrices or scaffolds with or without bone-inducing proteins such as the bone morphogenetic proteins, before such implants are used in larger more expensive animal models. For example, the boneinductive potential of demineralized bone matrix (DBM), previously taken from OVX rats, was studied in OVX rats (Cesnjaj et al., 1991). Finally, longer term studies which require several biopsies, or large blood samples, also are very difficult in such a small animal as the rat.

\section{Rabbits}

Aside from economic reasons, rabbits are common labo- 
ratory animals because of their size, temperament and availability of genetically homogeneous strains. They are comonly used in cardiovascular diseases, specifically in atherogenesis. There have been surprisingly few studies using the ovariectomized rabbit to study the effect of ovarian insufficiency on bone mass although this animal seems more popular to study bone ingrowth into implants and bone-implant interfaces. To determine the effect of testosterone and estrogen on bone density during bone growth, New Zealand White rabbits were selected because of their short developmental period and their faster bone turnover than primates (Gilsanz et al., 1988). Unlike other mammals such as the rat, mouse and guinea pig, rabbits achieve skeletal maturity (closure of epiphyseal plates) shortly after reaching complete sexual development at approximately 6 months (Gilsanz et al., 1988), and they show significant intracortical remodelling (Kimmel, 1996). Female growing rabbits were given prednisolone $(0.7 \mathrm{mg} / \mathrm{kg}$ per day for 5 months) to study corticosteroid-induced osteoporosis. Mechanical testing of vertebrae showed a significantly lower compressive strength and lower total bone mineral in the treated group (Grardel et al., 1994).

\section{Ferrets}

The ferret (an animal with Haversian remodeling) is a relatively new model for postmenopausal osteoporosis (Hartke, 1998). Like the rat, the OVX ferret exhibits bone loss in the proximal tibia (Mackey et al., 1995). They are easy to house, small in size and are a seasonally polyestrus. They are carnivores which may mean different metabolism of drugs. Ferrets have been used to study the effects of parathyroid hormone (PTH) but they would obviously be too small to study the optimum implant anchorage in osteopenic bone.

\section{Guinea Pigs}

The guinea pig is a popular research mammal due to its reproductive cycle. Like the human, guinea pigs have a long cycle, ovulate spontaneously, and have an actively secreting corpus luteum. Their small size allows them to be housed in less space, and less expensive than some of the larger models. However, like the rodent and chicken, their size prevents both large blood or bone sampling, and prevents their use as a model for human prostheses.

In a study of the effects of androgen and estrogen deficiency on skeletal homeostasis in adult guinea pigs, OVX showed no effect on bone volume (Vanderschueren et al., 1992). This finding is contrary to the effect of either natural or surgical menopause in the human. Because osteoporosis is mainly a disease of postmenopausal women, and estrogen deficiency in guinea pigs has no consequences on bone mass, this species seems unlikely to be a useful model for human osteoporosis. The guinea pig is also a poor model for glucocorticoid osteoporosis because, among other things, it has an unusual hypothalamic-pituitary-adrenal axis compared to other animals (O'Connell, 1999).

\section{Minipigs}

Where previously the size of the pig was a limiting factor in their widespread use as a model for research, the introduction of the minipig (and the micropig) has eliminated this problem. Although more expensive to acquire, minipigs at maturity weigh $60 \mathrm{~kg}$, while the commercial farm pig can weigh in excess of $150 \mathrm{~kg}$. This reduction in size translates into substantially less housing space, and greater ease of handling. The reproductive cycle of the pig is similar to that of the human in duration (18 - 21 days) and, like the human, is continuous. Another important similarity is the omnivorous diet of swine and the anatomy of the gastrointestinal tract; this is their most notable advantage over some other models.

Several features of the minipig skeleton are similar to humans. The skeleton displays extensive BMU-based remodeling in cancellous and metaphyseal cortical bone (Spurrel et al., 1965) and pigs possess a definable peak bone mass at 2.5-3 years of age (Bouchard et al., 1995). Pigs are one of the few animals where a syndrome of spontaneous vertebral fracture has been reported (Spencer, 1979). While pigs are quadrupeds (therefore have different loading patterns on the bone), they have a higher bone mass and denser trabecular network than humans (Mosekilde $e t$ al., 1993a,b). On the other hand like dogs, they are large enough to receive prosthetic implants and withstand repetitive bone biopsies and large volume blood sampling. Bone removal and deposition of trabecular and cortical bone occurs at a rate comparable with that of humans, and swine possess lamellar bone (Mosekilde et al., 1987).

The skeletal response to OVX in pigs is modulated by dietary calcium. In a study involving the OVX Sinclair S-1 minipig on a $0.75 \%$ calcium restricted diet, there were significant changes in remodeling parameters (e.g. an increase in resorptive cell function at the level of the remodeling unit). This led to significant alterations in bone structure (e.g. trabecular plate perforation), and a significant decline in bone mass and biomechanical competence of vertebral cancellous bone (Mosekilde et al., 1993a,b; Boyce et al., 1995). These findings suggest that the OVX calcium-restricted $(0.75 \%)$ Sinclair S1 minipig has potential as a model for studying the bone remodeling in humans and perimenopausal bone loss in women. The effect of OVX can be confounded in immature animals so skeletally mature sows were evaluated. OVX caused an $11 \%$ reduction in vertebral BMD in 12 months (Bouchard et al., 1997).

Both pigs and dogs have been used to evaluate bone active agents. For example, comparison of the effects of 1year treatment with sodium fluoride and the bisphosphonate, alendronate on bone quality (mechanical testing), and remodeling (histomorphometry) was determined in 9-mo-old minipigs (Lafage et al., 1995).

The metabolism of bone, the estrous cycle, and gastrointestinal function of the swine are positive features for this species as a model, but there are some disadvantages. The cost of the mini-pig, as well as its rarity in certain areas are logistical problems. If the larger farm pig is chosen, housing and handling are made more difficult, although technicians trained to work with the animals, as well as special equipment can alleviate these difficulties. Regardless of the breed, however, farm pigs are loud and can be aggressive, making them inconvenient to use on projects which require a large amount of handling and interaction.

\section{Sheep}

Before 1994, there were very few studies using sheep as an animal model of osteopenia and other aspects of 
orthopaedic research. However, advantages in the use of sheep are emerging because societal views about use of animals for research in general, is quickly changing. While larger than some of the previously mentioned animals, sheep are very docile and compliant. Sheep are food animals which are raised on the range and not individualized; hence the emotional attachment to sheep is not the same as companion animals such as dogs or cats. Furthermore, they are flock animals and suffer the least stress when they can be housed outdoors with minimal supervision, in groups of two or more. The husbandry of sheep greatly reduces housing costs. Finally, sheep are available in large numbers in many countries around the world so that largescale studies are possible.

Primary osteopenia in sheep is uncommon. In old age, a limiting factor for survival in sheep is dental health. Wear of teeth and teeth loss leads to gradual wasting and inanition, with bone loss. The changes observed in mandibular bone at various stages of development in sheep from several farms with different incidence of premature incisor loss, have been studied (Atkinson et al., 1982). Ourselves and others (Johnson et al., 1997), have rekindled interest in the ovine mandible as it relates to estrogen loss (see below). The effects of various therapeutic drugs, such as fluoride, on bone tissue were investigated by workers in France using sheep (Chavassieux, 1990; Chavassieux et al., 1991). The same laboratory used a sheep model to show that OVX induced an increase in bone formation beginning at 10 weeks after surgery and persisting at the 6th month (Pastoureau et al., 1989).

Since those reports, our group (Newman et al., 1995; Thorndike and Turner, 1999) and others (Pastoureau et al., 1989; Hornby et al., 1994; Atley, 1996; Geusens, 1996; O'Connell, 1999) have documented osteopenia in sheep following OVX as well as the response to various agents such as estradiol implants (Turner et al., 1995a,b; O'Connell, 1999), salmon calcitonin (Geusens et al., 1996), and the selective estrogen receptor modulator (SERM) raloxifene (Turner et al., 1999a). Our earlier findings showed a significant decline in cancellous bone volume (BV/TV\%) of the iliac crest following OVX (Turner et al., 1993). Subsequent studies (Turner et al., 1995a,b) demonstrated bone loss (measured by DXA) in the lumbar vertebrae following OVX (Turner et al., 1995a). These data and findings from other independent laboratories demonstrated that bone loss in the lumbar vertebrae of sheep following OVX was ameliorated by ERT.

We have used the aged OVX ewe to evaluate the selective estrogen receptor modulator (SERM) raloxifene. In a dose-response study $(0.02 \mathrm{mg} / \mathrm{kg}$ and $0.1 \mathrm{mg} / \mathrm{kg}$ administered subcutaneously), 6 months following OVX, we found improved BMD, vertebral trabecular bone density, and compressive strength with the higher dose of the SERM. Specifically, the spine BMD in the high-dose raloxifene group had increased $9.49 \pm 7.69 \%$, whereas the spine BMD in the OVX group decreased 5.40 \pm 8.97\%. (Turner et al., 1999a) (Fig. 1). The compressive strength of the vertebral trabecular bone was 2-3 times greater in the high-dose raloxifene group compared to other groups $(p<.001)$.

The skeletal changes seen in the proximal femur following menopause have been studied for many years and we

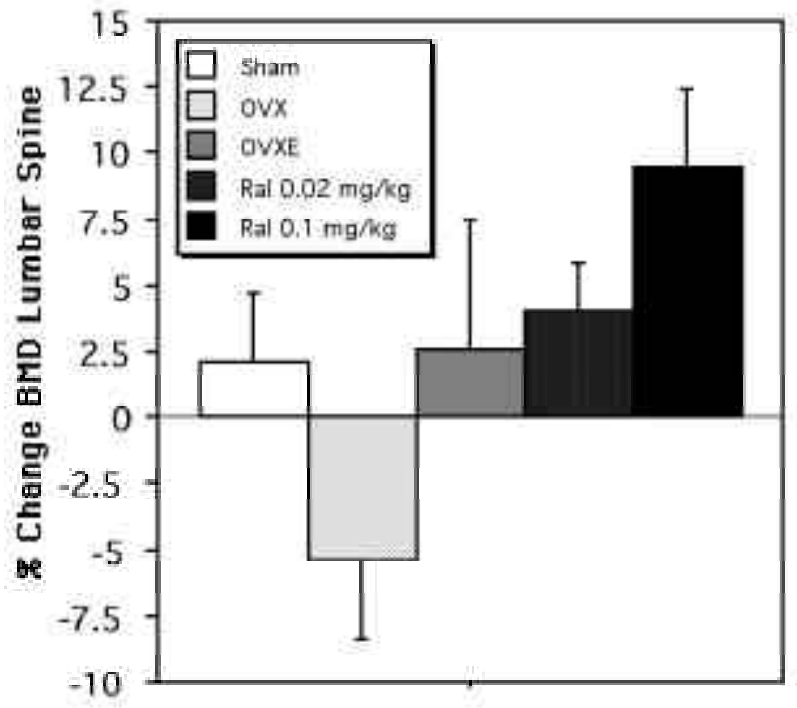

Figure 1. Percentage change (mean $\pm \mathrm{SE}$ ) in lumbar spine BMD after 6 months of treatment with estradiol implants (OVXE), and two doses of the SERM, raloxifene (see Turner et al., 1999a for details).

documented a statistically different Singh index in the proximal femur in OVX ewes compared to both young and old sheep (Turner et al., 1993). Although precise measurements of excised sheep femora using DXA are possible (Grier et al., 1996), one of the distinct disadvantages of using a quadruped (including dogs) for measuring longitudinal changes in BMD using DXA is the technical difficulties in positioning the animal to examine the femoral neck region. In longitudinal studies, it is critical that an identical region of interest is evaluated on a repeatable basis. Some researchers using DXA have experienced difficulties in edge detection when measuring ovine vertebrae (Deloffre et al., 1996), while others have overcome this by scanning only the central portion of the cancellous-rich vertebral body (O’Connell, 1999).

Seasonal changes in bone mass and biochemical markers in elderly women have been reported (Rosen et al., 1994). In a 24-month study in northern New England, significant seasonal changes in BMD, serum 25 hydroxyvitamin D and parathyroid hormone were seen; the greatest decline in measureable bone mass being in winter. Seasonal fluctuations such as this also occur in sheep and this must be addressed as a potential variable when using sheep in studies of osteopenia (Chavassieux et al., 1991; Hornby et al.; 1995, Turner et al., 1995b; O’Connell, 1999). Sheep living in more benign climates such as Australia may demonstrate less seasonal variation although this has not been documented. For these reasons, experiments using sheep should have not only the appropriate control groups, but if possible, span all four seasons to minimize seasonal changes. Seasonal variation is also related to the periods of seasonal anestrus, itself linked to the environmental photoperiod (Goodman, 1994). To evaluate the effect of salmon calcitonin on bone mass, compression (lumbar vertebrae and femoral neck), torsional stress (femoral neck only) and resonant frequency were measured in excised femoral neck and lumbar vertebral sam- 
ples from OVX sheep (Geusens, 1992; Geusens, 1996). In that study, bone mass was measured using DXA and dualenergy quantitative computed tomography (DEQCT). Sheep were used because "they possess skeletal turnover kinetics similar to humans". OVX resulted in decreased BMD measured by DXA and DEQCT and decreased resistance to rapid compression but not to torsion. Sheep have also been used as a model for glucocorticoid-induced bone loss (Fortune et al., 1989; O'Connell et al., 1993; Atley, 1996; O’Connell, 1999).

Several advantages of sheep include the temporal and quantitative similarities between the hormone profiles of ewes and women (Goodman, 1994). Although some breeds are seasonally polyestrous (cycles begin in the Fall in response to shortening periods of daylight), some breeds (e.g., Merino) can continue to cycle almost year-round (O’Connell, 1999). An OVX animal model with more frequent estrus cycles than, for example the dog, may prove to be more sensitive to estrogen deficiency. However sheep, like rats (Kalu, 1991) and many of the other animal models, do not have a clear-cut menopause at midlife that is characterized by accelerated bone loss.

One clear disadvantage of the use of sheep is their different gastrointestinal system. Studies where there is interest in the oral absorption of drugs (avoiding alteration of the drug by rumen microflora) either require the surgical insertion of an abomasal fistula, or stimulation of the oropharynx as the medication is delivered (to activate closure of the reticular groove).

A potentially relevant difference in mineral homeostasis between sheep and humans is their phosphorus metabolism. Urinary phosphate excretion is much lower in sheep and the gastrointestinal tract is the major route of phosphate elimination in this species (O’Connell, 1999).

The cortical bone of sheep is similar to other species of large domestic mammals. The bone of young sheep (less than 3-4 years of age) is plexiform and is a combination of woven and lamellar bone with functional similarities but with distinctly different patterns of deposition and organization (Newman et al., 1995). Like woven bone, plexiform bone is deposited rapidly but achieves better mechanical properties for large, rapidly growing animals such as the artiodactyls, cows, elephants and larger breeds of dogs. Plexiform bone is also found in humans in the medial side of the mandibular ramus and in growing children around the time of growth spurts (Martin and Burr, 1989). We have seen Haversian remodeling in sheep 7-9 years of age. As the ovine skeleton ages, one of the first places to see Haversian remodeling is the caudal aspect of the femur, while another place of such remodeling is the diaphysis of the radius and humerus (Newman et al., 1995).

Biochemical changes associated with skeletal disorders such as osteoporosis have probably been characterized more in sheep than any large animal. Measurement of the osteoblast product osteocalcin (OC) in sheep is well described in the literature. A radioimmunoassay (RIA) technique developed by French workers has shown that the increased serum OC levels in 7-year-old sheep are similar to those of 65-year-old women (Pastoureau et al., 1988, 1991). There is a high degree of homology between the human and ovine forms of the peptide (O'Connell, 1999).
This parameter has been closely correlated with the histomorphometric measurements from the iliac crest biopsies of these sheep (Pastoureau et al., 1991). Studies on the physiological influences and the effects of hormones on the production of OC suggest that the responses of ovine and human osteoblasts are similar under a variety of circumstances (Melick et al., 1988; Fortune et al., 1989). As in humans, plasma OC levels in sheep are high in the neonate and decline with age. To improve the understanding of cellular events in the ovine skeleton during pregnancy and postpartum, plasma OC levels were measured in age-matched nonpregnant, pregnant, and postpartum ewes (Farrugia et al., 1989). It was evident that osteoblast function underwent striking changes during pregnancy and the postpartum period. As in humans, ovine plasma OC remained low until delivery. Other studies of OC in sheep showed reduced levels during phosphate depletion and in response to exogenous glucocorticoids, and elevated levels induced by 1, 25-dihydroxyvitamin D3 (Fortune et al., 1989; O’Connell et al., 1993). A biochemical and histomorphometric study of glucocorticoid-induced inhibition of osteoblastic bone formation has also been studied in sheep (Chavassieux et al., 1993).

The activity of bone-specific alkaline phosphatase (BSAP), an isoenzyme involved in bone formation and skeletal mineralization, was found to be significantly decreased in both a sham group and a group which underwent OVX supplemented with estradiol implants (OVXE) (Turner et al., 1995a). This demonstrated that bone loss in the lumbar vertebrae of sheep following OVX was ameliorated by ERT. The increase in activity of BSAP in the OVX group was highly indicative of accelerated bone turnover and was in agreement with the changes seen in aging adult humans, particularly in women at menopause (Duda et al., 1988; DeSouza et al., 1996). Human studies show discordant results for plasma osteocalcin and BSAP (Duda et al., 1988) which may reflect on the different roles by these markers in osteoblast function (O’Connell, 1999).

The collagen crosslink bone resorption markers pyridinoline and deoxypyrodinoline have been measured in the urine of sheep. One study found these markers useful for differentiation of changes induced by lactation, glucocorticoid treatment and ovariectomy (Atley, 1996). Like the data from measurements of bone mass (Rosen $e t$ al., 1994) the interpretation of biochemical markers of bone turnover continue to be complicated by circadian and seasonal fluctuations (Blumsohn and Eastell, 1992). The diurnal patterns in markers of bone turnover in sheep, closely resemble those in humans, with turnover activity elevated late at night or early morning (O'Connell, 1999). Therefore it is essential to document the physiological variations in bone marker levels so that their experimental use is as informative as possible.

Future studies using OVX sheep should investigate other newer biochemical markers indicative of fragments of type I collagen synthesis and degradation that are most likely to reflect bone turnover (DeSouza et al., 1996; Thorsen et al., 1996; O' Connell, 1999). Such markers include the carboxy-terminal propeptide (PICP) to reflect bone matrix synthesis and the carboxy-terminal telopeptide (Ctelopeptide or ICTP) which reflects bone matrix degrada- 
tion. These biochemical markers will be important in monitoring new therapeutic regimens for osteoporosis when using animal models.

Like dogs and pigs (and most primates), the size of sheep allows us to meet other criteria for a model of osteoporosis. Specifically they are large enough to accommodate prosthesis implantation, substantial blood and urine sampling, and ample iliac crest biopsies (histomorphometry). This will facilitate research to correlate events at the clinical, tissue, cellular and biochemical levels.

To evaluate if extremely low magnitude mechanical stimulus (LMMS) can be osteogenic, 18 adult female sheep were separated into two groups, those subjected to LMMS and untreated controls. For 20 minutes per day, sheep stood confined in a chute such that the hind limbs were subjected to vertical ground based vibration (Rubin et al., 1997). Bone density at various sites was measured using DXA at different time points. Six months exposure to a brief ( $20 \mathrm{~min})$ extremely low intensity $(<10$ microstrain $)$, through this vibrational loading was shown to be osteogenic in those sites subjected to transmission of the vibration (Rubin et al., 1997). Because of their docile compliant nature, the sheep were well behaved and easy to train to stand on this device. Other large animals would be less suitable for this type of study.

While sheep may prove to be a suitable model for the study of osteoporosis and related conditions, there are other questions that the researcher who chooses this model must resolve. We must identify where skeletal remodeling is the most and characterize further, the seasonal and circadian fluctuations in bone density, biochemical markers and histomorphometry of the iliac crest, as well as fluctuations associated with parity, pregnancy and number of offspring and lactation. The existence of such natural variation requires researchers to perfect non-invasive measurements of BMD with state-of-the-art equipment such as DXA or pQCT at known intervals throughout the seasons. The protocols and software for these modern methods of densitometry, although designed for human clinical use, are readily adapted to the axial and appendicular skeleton of the sheep owing to the similar size of the two species (Turner et al., 1994). Positioning a quadruped (usually requiring general anesthesia), allowing an identical region of interest to be evaluated on a repeatable basis for longitudinal measurements of BMD, will always be a challenge for researchers using animals. The use of positioning devices has been recommended to greatly improve measurement precision of excised sheep bones (Kaymakci and Wark, 1994). Questions about natural fluctuations of BMD will remain unanswered until sheep are studied more intensively and should not be regarded as disadvantages. Although DXA is a well-accepted technique in clinical use (Blake $e t$ al., 1999), more accurate equipment such as pQCT is now available. Furthermore, the long duration of current studies is due to the limited sensitivity of DXA and more accurate methods such as pQCT will allow shorter duration and more economical studies. (Rüeggsegger et al., 1996; Müller et al., 1998).

Although hip joint of dogs have been "the industry standard" for in vivo evaluation of the biology of the host femur to stem design and coating, and wear debris, there are more reports on the use of sheep (Bruns et al., 1996; Vidovszky et al., 1996; Goodship et al., 1998), and goats (Schreurs et al., 1996; Bhumbra et al., 1999) for such studies. Forces exerted upon the hip joint of sheep are comparable to those of humans (Bergmann et al., 1984).

The peripheral production of estrogen-related compounds from body fat is well documented in women and along with greater mechanical loading of bones is likely to contribute to the low incidence of fractures in large patients (Dawson-Hughes et al., 1993; Ricci et al., 2001). The production of other sex hormones from body fat in sheep (e.g. aromatization of androgens) such as estrone and estriol, as well as adrenal androgens (dehydroepiandrosterone and androstendione) may explain why bone loss following ovariectomy in sheep (and other animal models), is variable and not as severe compared to women. This limits somewhat, the use of oestrogen-deficient animals for this type of research. True calcium-deficient diets are difficult to achieve in sheep due to the low dietary requirements of calcium in skeletally mature non-pregnant, or non-lactating ewes. To achieve the osteopenia to the degree seen in human osteoporosis, feeding of a calcium-wasting diet to ovariectomized sheep is currently under study. Such a diet can be successfully and safely achieved by feeding sheep a ration relatively high in anionic salts (Takagi and Block, 1991a,b,c).

The questions that must be answered particularly with respect to the sheep are: 1) What extrinsic factors are likely to confound the bone loss following ovarian hormone deficiency? Such extrinsic factors may include breed, diet (e.g., Ca:P ratio), exposure to sunlight (e.g. sunny or cloudy environment); 2) What intrinsic factors can confound OVX (e.g. are there other steroids such as 17-alpha estradiol originating from adrenals or adipocytes, that can compensate for the loss of 17-beta estradiol ; 3) At what time of the year should OVX be performed to demonstrate the most rapid bone loss? In other words, should OVX be performed in anestrus prior to when estrus cycles begin or during the breeding season when estrus cycles are occurring regularly?

Most animal models have used females and osteoporosis in the male has been largely ignored despite the fact that it is a growing problem in older men (Slemenda et al., 1992) and men with delayed puberty (Finkelstein et al., 1992). Future studies using male animals would be of interest but the practicality and availability of male sheep (rams) might be a limiting factor for this model to study the different aspects of osteoporosis in men.

\section{Evaluation of Implants in Osteopenic Bone}

\section{Appendicular skeleton}

Many implants (e.g. total hip replacement) are placed in persons over 65 years old and many of these patients are postmenopausal women with osteoporosis. Achieving a stable biological interface in the axial, appendicular and mandibular bone of the elderly, osteopenic postmenopausal patient in a shorter period of time is therefore of great interest (Eckhoff et al., 1995; Turner et al., 1996a,c; Mori et al., 1997; Fujimoto et al., 1998; Seebeck et al., 2000; 

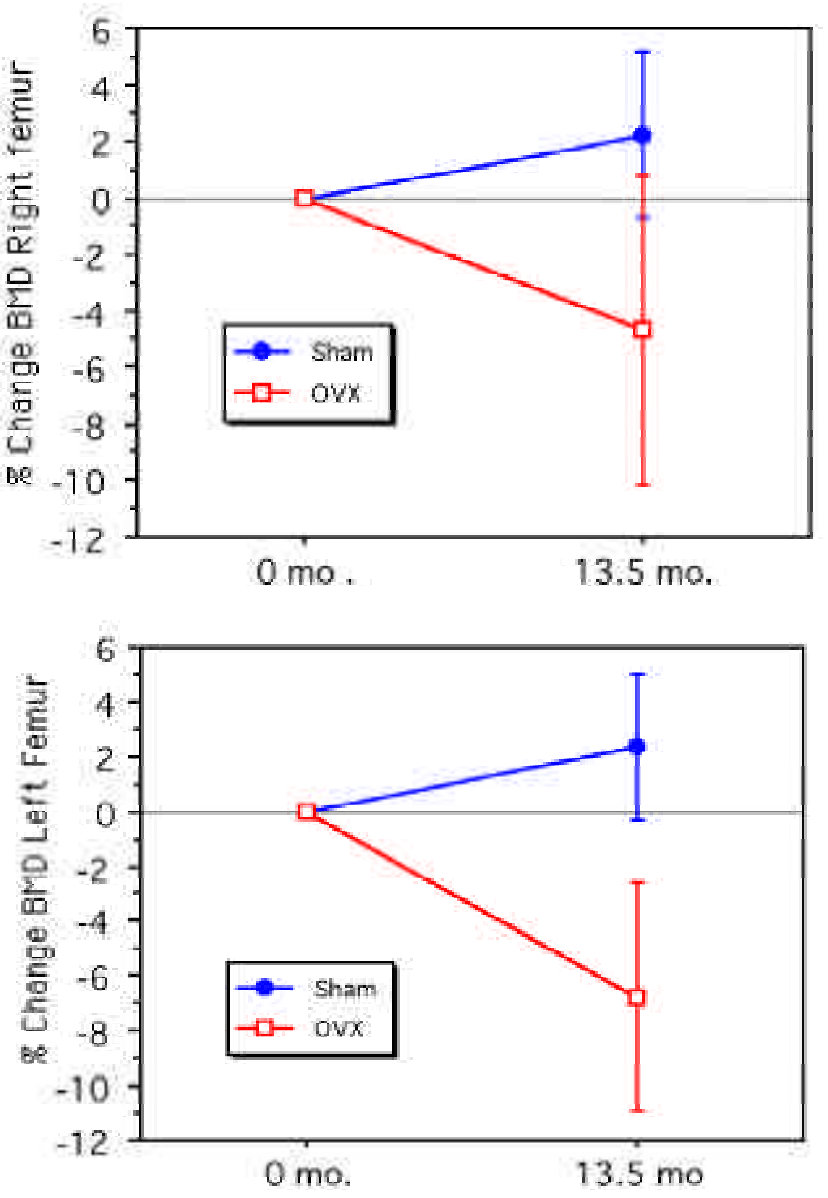

Figure 2 (a, b). Percentage change $($ mean $\pm S E)$ in time of BMD of the left and right distal femora in the sham and OVX ewes at 13.5 months (see Turner et al., 1998 for details).

Fini et al., 2001). It is intuitive that an osteoconductive ceramic coating on hip implants in these osteoporotic patients may improve fixation. For example, we found that a good model to test the effectiveness of a ceramic coating such as HA for use in postmenopausal women with osteoporosis, is the distal femur of the aged OVX ewe (Turner et al., 1998). In this study we determined if a ceramic coated (Peri-Apatite $^{\mathrm{TM}}$ ) metal implant, placed in the distal femur of the ovariectomized ewe, would be stronger than an implant that was not coated with the ceramic. Skeletally mature ewes were subjected to OVX or sham operation (Sham) and DXA of both distal femora was performed. Twelve months following OVX or Sham procedure, Peri-Apatite ${ }^{\mathrm{TM}}$ coated and uncoated grit-blasted titanium alloy plugs were placed in the subtrochlear region of both distal femora. At 6 weeks after implantation, the animals were euthanized and BMD of distal femora was again measured. Uncoated and coated plugs were subjected to push-out tests using an Instron machine to determine the strength of the interface. BMD in the OVX group was less than the sham group in both the left and right distal femora (Fig. 2 a,b). Two scans of each bone were performed and a mean BMD of each ROI was determined.

The decrease of BMD in the left and right distal femora provided an osteopenic environment to study the osseointegration of the implants. The study demonstrated that ceramic-coated implants improved osseointegration at 6 weeks in both the osteopenic and the "normal" bone of the distal femur. Furthermore, the improvement in biologic fixation was more pronounced in the osteopenic bone. This osteopenic environment in the distal femora in OVX sheep is a site where other implants, coatings and growth factors could be evaluated.

\section{Axial skeleton}

Pedicle screw fixation is one of several methods used for lumbar interbody fusions for disorders such as internal disc disruption, tumors, instability, and infection. An estrogen-deficient animal model that shows loss of bone in the lumbar vertebrae would be of great value to those interested in techniques to improve pullout strength and transverse bending stiffness in fixation of osteoporotic spines. Using this model, one can investigate improvement in implant design or techniques to augment existing implants such as implant coatings or bioactive ceramics injected directly into osteoporotic vertebral bodies (vertebroplasty; see below).

\section{Mandible}

There is increasing interest in the relationship between systemic osteoporosis (of the hip and the spine) and bone loss in the mandible and maxilla (Birkenfeld et al., 1999). Previously, each disease was studied as a single entity and the relationship between the two has been largely ignored. Loss of bone from the oral skeleton or the maxillofacial complex significantly impacts the health and quality of patients lives, most often the elderly. Oral bone loss most commonly results from periodontal disease, resorption of alveolar ridges following tooth extraction, or combinations of both. Ovariectomy has been shown to decrease the bone area fraction and stiffness of the aging rat (Elovic $e t$ al., 1995). Because of the size of the mandible in small animals such as the rat, a suitable large animal model exhibiting bone loss of the maxillofacial region would be of great interest in dental medicine and those studying oral implants. In one study from our laboratory (Turner et al, 1996b), skeletally mature ewes were divided into four groups: sham treated (Sham), OVX, OVX plus one estradiol (E2) implant (OVXE) and OVX plus two E2 implants (OVX2E). At the end of 12 months, BMD of 4 regions of interest (ROI), R1, R2, R3 and R4 of excised mandibles using DXA was measured (Fig.3). Two scans of each bone were performed and

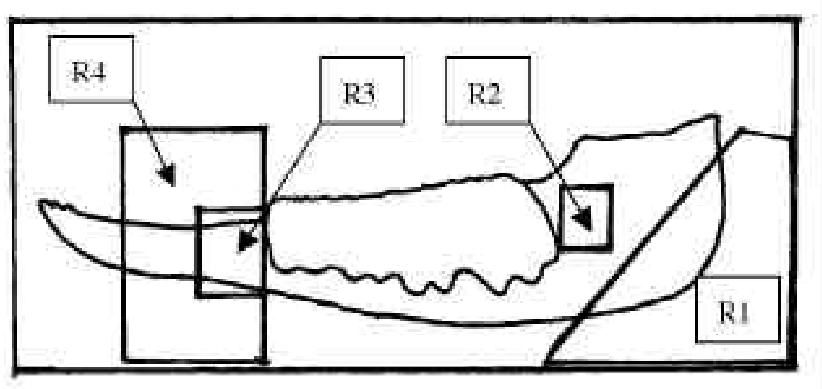

Figure 3. The 4 ROI for which BMD was determined, where R1was the angle of the mandible (excluding the mandibular canal), R2 was the area distal to last molar, $\mathrm{R} 3$ was mesial to mental foramen and R4 was mesial to premolars and distal to incisors (see Turner et al., 1996 b for details). 


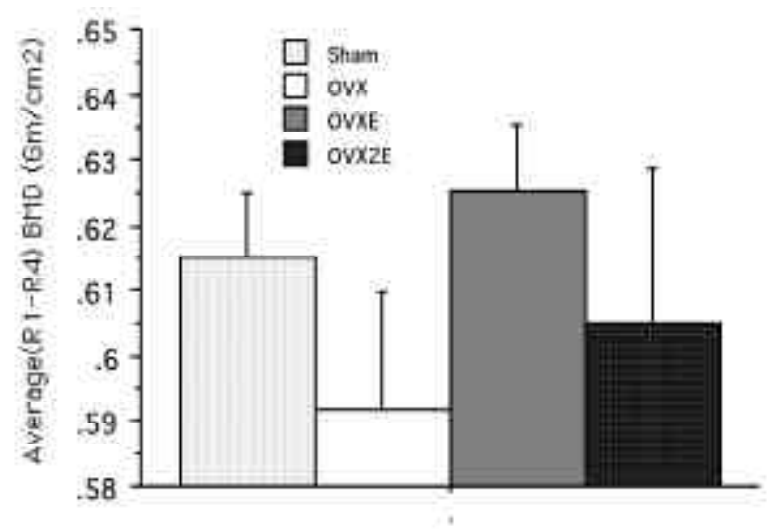

Figure 4. Mean and standard error of BMD of the 4 regions of interest in the mandible in Sham, OVX, OVXE and OVX2E groups (see Turner et al., 1996b for details).

a mean BMD of each ROI was determined. We demonstrated modest decrease in mandibular BMD after a year of estrogen deficiency (Fig. 4). We were encouraged by this result (changes did not reach statistical significance because power was limited in this study), therefore, larger numbers of animals or longer periods of follow-up would be needed if the sheep is to be used as a model for oral bone loss. Others (Johnson et al., 1997) have also documented an increase in the prevalence and severity of sites of horizontal and vertical alveolar bone loss after one year following OVX in sheep.

These studies, based on DXA of the mandible, provided evidence that systemic bone loss in OVX ewes is accompanied by oral bone loss. Further, there is evidence that the prophylactic effect of estrogen occurred with oral bone loss as well as with osteoporosis. These studies support the epidemiological data from one population of older women in a California retirement community, where estrogen users had retained more natural teeth than nonusers (Paganini-Hill, 1995), as well as work by others (Jacobs et al., 1996) who demonstrated that ERT had a positive affect on bone mass in the mandible and lumbar spine.

We also studied mandibular bone loss in OVX sheep using DXA, and a dose-response to the SERM, raloxifene (Turner et al., 1999b). The two different doses of raloxifene $(0.1 \mathrm{mg} / \mathrm{kg} / \mathrm{day}$; and $0.02 \mathrm{mg} / \mathrm{kg} /$ day; $)$ were based on results of studies in rats and a kinetic study performed in our laboratory. Our results indicated that in this model, estrogen depletion caused a subtle loss of bone in the mandible, but raloxifene at a dose of $0.1 \mathrm{mg} / \mathrm{kg}$ significantly increased its bone mass. A lower dose of raloxifene was ineffective (Fig. 5). This is the first report to my knowledge, of the effect of a SERM on mandibular bone density in an estrogen-deficient animal model.

The OVX ewe may be a useful large animal model in the study of mandibular atrophy and its manifestations. Although associations have been made between the extent of reduction of the residual ridges and osteoporosis in humans, this animal model may allow a more controlled study of osseointegration of dental implants or response to bone-graft substitutes, in osteopenic bone. The model may also be useful in the study of SERM's and their effect on implant fixation in osteopenic the mandible (Turner $e t$

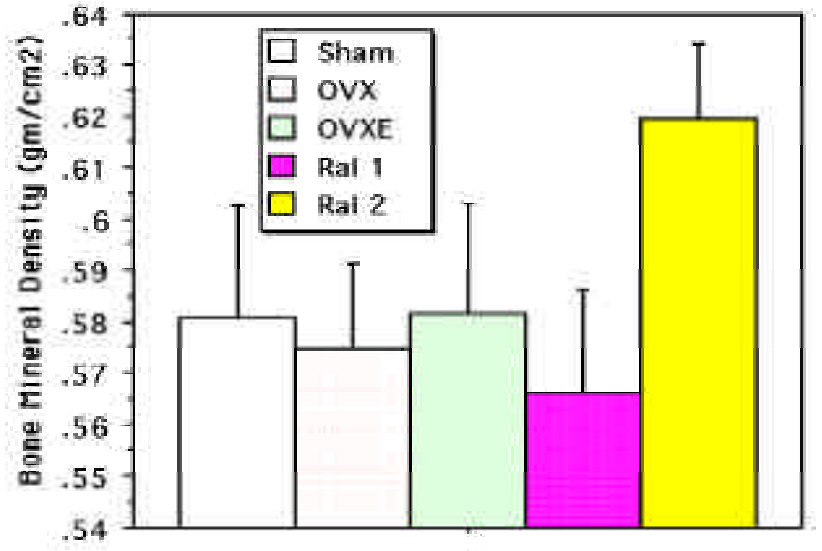

Figure 5. Mean bone mineral density $( \pm \mathrm{SE}$; gm/ $\mathrm{cm} 2)$ of the four regions of interest of the right mandible in five treatment groups (see Turner et al., 1999b for details).

al., 1999b).

\section{Vertebroplasty}

Osteoporotic vertebral fractures are common in the elderly, occurring in about $20 \%$ of individuals older than 70 years of age. They are more common than fractures of the hip, are painful and cause kyphotic deformity. Conventional treatment of these fractures is usually non-operative and relies in prescription of calcium carbonate, estrogen, bisphosphonates, or calcitonin, with analgesics for pain relief (Melton et al., 1989; Schildhauer et al., 1999). Unfortunately, these treatments often do not prevent further collapse of the vertebral bodies. Operative treatment is usually recommended only for fractures with gross deformities or with neurologic impairment and is intended to break the cycle of pain and inactivity followed by progression of osteoporosis. Unfortunately, the incidence of complications during and after such procedures is higher in the older osteoporotic population most at risk for such fractures. Percutaneous vertebroplasty was introduced as a therapeutic alternative for the treatment of pain associated with compression fractures (Mathis et al., 1998; Belkoff $e t$ al., 1999). The ability to reconstruct the vertebral body with an osteoconductive material would be an attractive improvement over intravertebral injection of polymethylmethacrylate cement (PMMA). The conventional use of PMMA involves risks of extravasation and thermal damage to nerves and other local tissues (Brantley and Mayfield, 1999).

Development of a ceramic that is non exothermic, is osteoconductive and is similar to bone chemically is where the future of vertebroplasty lies. This bone substitute would act as a filler for bone defects such as seen in osteoporotic spinal fractures. The development of such a treatment would require that the cement has handling properties to allow it to be injected into a vertebrae and and not cause an adverse biological reaction.

The suction-injection technique used in the in vitro study of Schildhauer and coworkers was more effective (provided better infiltration) than injection alone (Schildhauer et al., 1999). This technique allowed more than half of the vertebral body to be infiltrated with apatite 

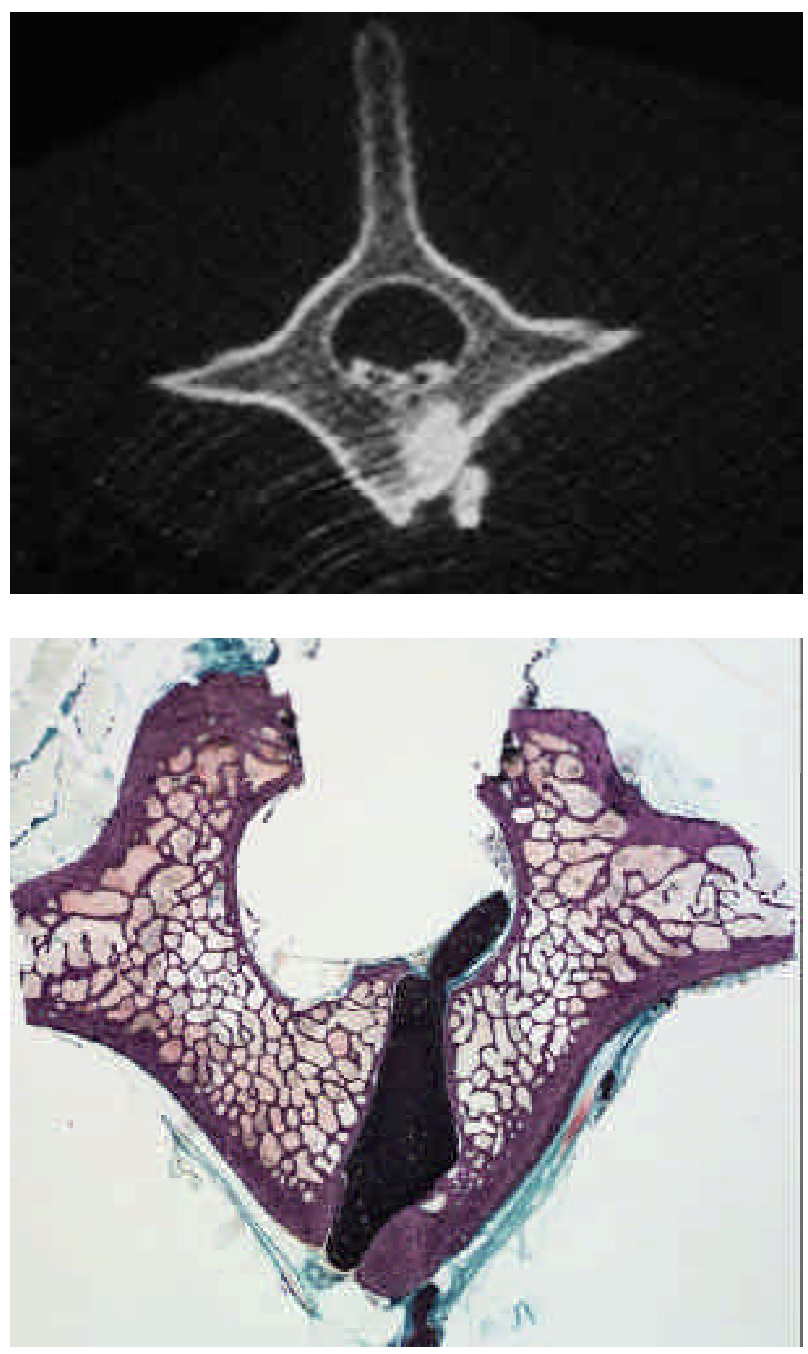

Figure 6. (a) CT scan 3 months post-vertebroplasty showing example of epidural leakage of PMMA. There were no histological changes or neurological signs as a result of the leakage. (b) Transverse section through a vertebral body at 3 months postvertebroplasty showing epidural leakage of BoneSource ${ }^{\circledR}$. There were no histological changes or neurological signs as a result of the leakage.

cement.

Extrapolation of in vitro results in cadaver studies to a human clinical situation will require in vivo studies using animals. A large animal model of sufficient is a logical model to investigate such compounds. For example, the ovariectomized calcium-restricted $(0.75 \%)$ Sinclair S1 minipig or the aged OVX ewe both have potential as a models for studying vertebroplasty as there is ample documentation of bone loss of the lumbar vertebrae following OVX in these species (see above). On the other hand, it would be technically difficult to use a dog the size of a beagle for vertebroplasty research owing to the size of the vertebral body for ceramic injections. To my knowledge, there are no studies documenting bone loss of the lumbar vertebrae in goats.

The geometry of the vertebral body of quadrupeds (pigs, goats and sheep) will make the compressive mechanical testing more difficult than Schildhauer and others used for testing of cadaveric vertebral bodies of humans
(Schildhauer et al., 1999). However, osteoporotic spines of quadrupeds that have injected with bone substitutes can be examined histologically to document the osteoconductive nature of the cement and its ability to be remodeled as well as any untoward effects on surrounding soft tissues including nerves (Fig. 6 a,b).

The technique of intravertebral body reconstruction of osteoporotic spines with an injectable ceramic or osteoconductive bone substitutes could provide better clinical results than those current treatment with acrylic cement. These bone substitutes have already been used in clinical trials for fracture care, filling defects due to tumors and fusion procedures, with healing rates similar to those obtained with autogenous grafts (Van Heest and Swiontkowski, 1999). Bone substitutes could also be used as a carrier matrix for the osteoconductive bone morphogenetic proteins (13 at the time of writing this review) such as rhBMP-2 and rhBMP-7. The future of bone-graft substitutes and complementary substances for vertebroplasty will depend upon evaluation in a large animal model with a vertebral body of practical size.

One limitation to the use of sheep for evaluation of vertebroplasty is the higher bone density and breaking strength compared to humans (Aerssens et al., 1998). In this study, samples were taken from skeletally immature animals (1-2 years-old) which may not be representative of adult sheep bone, which further emphasize the importance in using skeletally mature animals ( $>3.5$ years), rather than those seen in most slaughter houses destined for market. Furthermore, vertebrae from animals have a significantly thicker cortical shell (the primary envelope for strength) so that the maximum load prior to fracture may mask positive or negative changes in cancellous bone of the vertebrae (Hartke, 1999). This may also mask the positive effect of vertebroplasty.

\section{Conclusions}

This review has discussed some features of the different animal models for osteoporosis and osteopenia. Animal models for these conditions have more than just a few differences from humans and there are many animal model studies that are not yet adequately validated by corresponding data from human patients (Lo, 1996). There is no animal model that exactly mimics the condition of postmenopausal osteoporosis and one must know the limitations of the different animal models. However, some characteristics may be similar and these models provide excellent opportunities to mimic specific aspects of human disease (Hartke, 1999). Investigators must be prepared to use two perhaps three, different species to fully evaluate a new therapeutic agents or implants to be tested in osteopenic/ osteoporotic bone, with more emphasis should be placed on the use of male animals. To produce severely osteopenic bone comparable to that seen in humans, a combination of estrogen deficiency following ovariectomy, plus a calciumwasting diet in skeletally mature sheep, should be further investigated. Although FDA requires preclinical studies in animals to evaluate agents interned to treat osteoporosis in both rats and a larger animal, in-vivo animal experiments will taper off with more emphasis being placed on 
the basic bone physiology of each animal model.

\section{Acknowledgements}

The studies performed by the author and colleagues were funded by the following: Howmedica (Rutherford, NJ), Lilly Research Laboratories (Indianapolis, IN), National Institutes of Aging (RO3 AG 14367-01).

\section{References}

Abe T, Chow JWM, Lean JM, Chambers TJ. (1993) Estrogen does not restore bone lost after ovariectomy in the rat. J Bone Miner Res 8: 831-838.

Aerssens, J, Boonen S, Lowet G, Dequeker J. (1998) Interspecies difference in bone composition, density and quality; Potential implications for in vivo bone research. Endocrinology 139: 663-670.

Atkinson PJ, Spence JA Aitchison G, Sykes AR. (1982) Mandibular bone in ageing sheep. J Comp Path 92: 51-67.

Atley LM (1996). Biochemical Markers of Bone Resorption. Doctoral Thesis, Department of Medicine, The University of Melbourne, Australia.

Barlet JP, Coxam V, Davicco MJ, Gaumet N. (1994) Modèles animaux d'ostéoporose post-ménopausique. (Animal models for post-menopausal osteoporosis) Reprod Nutr Rev 34: 221-236.

Belkoff SM, Erbe EM, Fenton DC, Mathis JM (1999) Biomechanical comparison of two bone cements for use in vertebroplasty. Proc Orthop Res Soc, Anaheim, CA. p. 1006.

Bergmann G, Siraky J, Rohlmann A. (1984) A comparison of hip joint forces in sheep, dog and man. J Biomechanics 17: 907-921.

Birkenfeld L, Yemini M, Kase NG, Birkenfeld A. (1999) Menopause-related oral alveolar bone resorption:A review of relatively unexplored consequences of estrogen deficiency. Menopause 6: 129-133.

Blake GM, Wahner HW, Fogelman I. (1999) The Evaluation of Osteoporosis: Dual Energy X-ray Absorptiometry and Ultrasound in Clinical Practice ( $\left.2^{\text {nd }} e d n\right)$. Martin Dunitz, London,.

Bloebaum RD, Ota DT, Skedros JG, Mantas JP. (1993) Comparison of human and canine external femoral morphologies in the context of total hip replacement. J Biomed Mater Res 27: 1149-1159.

Blumsohn A, Eastell R (1992). Prediction of bone loss in postmenopausal women. Eur J Clin Invest 22: 764-766.

Bouchard GF, Durham HE, McOsker JE, Krause GF, Ellersieck MR, Reddy CS (1995) Determination of the peak bone mass and whole body composition in Sinclair miniature swine. J Bone Miner Res 10(Suppl): S476.

Bouchard GF, Boyce R.W, Paddock CL, Durham E, Reddy CS, Tumbleson ME, Schook LB. (1997) Standardization of an adult Sinclair miniature swine osteopenia model-preliminary results. J Bone Miner Res 12(Suppl): $\mathrm{T} 500$.

Boyce RW, Franks AF, Jankowsky ML, Orcutt CM, Piacquadio AM, White JM, Bevan JA. (1990) Sequential histomorphometric changes in cancellous bone from ovariohysterectomized dogs. J Bone Miner Res 5: 947-953.

Boyce RW, Ebert DC, Youngs TA, Paddock CL,
Mosekilde Li, Stevens ML, Gundersen HJG. (1995) Unbiased estimation of vertebral trabecular connectivity in calcium-restricted ovariectomized minipigs Bone 16: 637-642.

Boyce RW, Paddock CL, Franks AF, Jankowsky ML, Eriksen EE. (1996) Effects of intermittent hPTH (1-34) alone and in combination with $1,25(\mathrm{OH}) 2 \mathrm{D} 3$ or risedronate on endosteal bone remodeling in canine cancellous and cortical bone. J Bone Miner Res 11: 600-613.

Brantley A, Mayfield J. (1999) New techniques for augmenting pedicle screw fixation in osteopenic bone. Proc Orthop Res Soc, Anaheim, CA. p. 996.

Bruns DP, Olmstead ML, Litsky AS. (1996) Technique and results for total hip replacement in sheep: An experimental model. Vet Comp Orthop Traumatol 9: 158-164.

Bhumbra RS, Walker PS, Berman AB, Emmanual J, Barrett DS, Blunn GW. (1999) A total hip arthroplasty model. Proc Orthop Res Soc, Anaheim, CA. p. 877.

Cesnjaj M, Stavljenic A, Vukicevic S. (1991) Decreased osteoinductive potential of bone matrix from ovariectomized rats. Acta Orthop Scand 62: 471-475.

Chavassieux P. (1990) Bone effects of fluoride in animal models "in vivo". A review and a recent study. J Bone Miner Res 5(suppl. 1): S95-S99.

Chavassieux P, Pastoureau P, Boivin G, Chapuy MC, Delmas PD, Meunier PJ. (1991) Dose effects on ewe bone remodeling of short-term sodium fluoride administration-a histomorphometric and biochemical study. Bone 12: 421427.

Chavassieux P, Pastoureau P, Chapuy MC, Delmas PD, Meunier PJ. (1993) Glucocorticoid-induced inhibition of osteoblastic bone formation in ewes: a biochemical and histomorphometric study. Osteoporos Int. 3: 97-102.

Davidson MK, Lindsey JR, Davis JK. (1987) Requirements and selection of an animal model. Isr J Med Sci 23: 551-555.

Dawson-Hughes B, Krall EA, Harris S. (1993) Risk factors for bone loss in healthy postmenopausal women. Osteoporosis Int Suppl. 1: S27-S31.

Dempster DW, Birchman R, Xu R, Lindsay R, Shen V. (1995) Temporal changes in cancellous bone structure of rats immediately after ovariectomy. Bone 16: 157-161.

DeSouza MJ, Prestwood KM, Luciano AA, Miller BE, Nulsen JC. (1996) A comparison of the effect of synthetic and micronized hormone replacement therapy on bone mineral density and biochemical markers of bone metabolism. Menopause 3: 140-148.

Draper HH. (1985) Osteoporosis. In: Advances in Nutritional Research. Plenum Press. New York, pp. 172-186.

Drezner MK, Nesbitt T. (1990) Role of calcitriol in prevention of osteoporosis: Part I. Metabolism 39(Suppl): 1823.

Duda RJ, O’Brian JF, Katzman JA, Peterson JM, Mann KG, Riggs BL. (1988) Concurrent assays of bone Gla-protein and bone alkaline phosphatase: effects of sex, age and metabolic bone disease. J Clin Endocrinol Metab 66: 951957.

EckhoffDG, Turner AS, Aberman HM . (1995) Effect of Age on Bone Formation around Orthopaedic Implants. Clin Orthop 312: 253-260.

Elovic RP, Hipp JA, Hayes WC. (1995) Ovariectomy decreases the bone area fraction of the rat mandible. Calcif 
Tissue Int 56: 305-310.

Farrugia W, Fortune CL, Heath J, Caple IW, Wark JD (1989). Osteocalcin as an index of osteoblast function during and after ovine pregnancy. Endocrinology 125: 17051710.

Faugere M-C, Friedler RM, Fanti P, Malluche HH. (1990) Bone changes occurring early after cessation of ovarian function in beagle dogs-A histomorphometric study employing sequential biopsies. J Bone Miner Res 5: 263-271.

Fini M, Giavaresi G, Torricelli P, Krajewski A, Ravaglioli A, Belmonte MM, Biagini G, Giardino R. (2001) Biocompatibility and osseointegration in osteoporotic bone. a preliminary in vitro and in vivo study. J Bone Joint Surg 83B: 139-143.

Finkelstein JS, Neer RM, Biller BMK, Crawford JD, Klibanski A. (1992) Osteopenia in men with a history of delayed puberty. N Engl J Med 326: 600-604.

Fortune CL, Farrugia W, Trensham J, Scoggins BA, Wark JD. (1989) Hormonal regulation of osteocalcin plasma production and clearance in sheep. Endocrinology 124: 2785-2790.

Forwood MR, Burr DB, Takano Y, Eastman DF, Smith PN, Schwardt JL. (1995) Risedronate treatment does not increase microdamage in the canine femoral neck. Bone 16: $643-650$.

Fox RR, Laird CW. (1970) Sexual cycles. In: Reproduction and Breeding Techniques for Laboratory Animals. Hafez ESE (ed). Lea \& Febiger, Philadelphia. pp. 107-122.

Frost HM, Jee WSS. (1992) On the rat model of human osteopenia and osteoporoses. Bone Miner 18: 227-236.

Fujimoto T, Niimi A, Sawai T, Ueda M. (1998) Effects of steriod-inducec osteoporosis on osseointegration of titanium implants. Int J Oral Maxillofac Implants. 13: 183-189.

Gaumet N, Seibel MJ, Braillon P, Giry J, Lebecque MJ, Coxam V, Rouffet J, Delmas PD, Barlet JP. (1996) Influence of ovariectomy on bone metabolism in very old rats. Calcif Tissue Int 58: 256-262.

Geusens P. (1992) Photon Absorptiometry in Osteoporosis. Bone Mineral Measurements in Animal Models and Humans. Doctoral Thesis, Faculty of Medicine, Catholic University of Leuven, Belgium (Katholieke Universiteit Leuven) .

Geusens P, Boonen S, Nijs J, Jiang Y, Lowet G, Van Auderkercke R, Huyghe C, Caulin F, Very JM, Dequeker J, Van der Perre G. (1996) Effect of salmon calcitonin on femoral bone quality in adult ovariectomized ewes. Calcif Tissue Int 59: 315-320.

Gilsanz V, Roe TF, Gibbens DT, Schulz EE, Carlson ME, Gonzalez O, Boechat MI. (1988) Effect of sex steroids on peak bone density of growing rabbits. Am J Physiol 255: E416-E421.

Goodman RL. (1994) Neuroendocrine control of the ovine estrous cycle. In: Physiology of Reproduction (2nd ed.). Knobil E, Neill J (eds.). Raven Press, New York, NY. pp. 659-709.

Goodship AE, Lawes TJ, Green J, Eldridge JD, Kenwright J. (1998) The use of bisphosphonates to inhibit mechanically related bone loss in aseptic loosening of hip prostheses. Proc Orthop Res Soc, New Orleans, LA. p. 2.

Goulding A, Gold E, Lewis-Barned NJ. (1996) Effects of hysterectomy on bone in intact rats, ovariectomized rats, and ovariectomized rats treated with estrogen. J Bone Miner Res 11: 977-983.

Grardel B, Sutter B, Flautre B, Viguier E, Lavaste F, Hardouin P. (1994) Effects of glucocorticoids on skeletal growth in rabbits evaluated by dual-photon absorptiometry, microscopic connectivity and vertebral compressive strength. Osteoporosis Int 4: 204-210

Grier SJ, Turner AS, Alvis MR. (1996) The Use of DualEnergy X-Ray Absorptiometry(DXA) in Animals: A Review. Investigative Radiol 31: 50-62.

Grisso JA, Capezuti E, Schwartz A. (1996) Falls and risk factors for fractures. In: Osteoporosis Marcus R, Feldman D, Kelsey J (eds.). Academic Press, San Diego. pp. 599611.

Grynpas MD, Kasra M, Dumitriu M, Nespeca R, Very JM, Mertz B. (1994) Recovery from pamidronate (APD): A two-year study in the dog. Calcif Tissue Int 55: 288-294.

Hartke J R. (1998) Non-primate models of osteoporosis. Lab Anim Sci 48: 623-629.

Hartke JR. (1999) Preclinical development of agents for the treatment of osteoporosis. Toxicologic Path 27: 143147.

Harvey EJ, Bobyn JD, Tanzer M, Stackpool Gj, Krygier JJ, Hacking SA. (1999) Effect of flexibility of the femoral stem on bone-remodeling and fixation of the stem in a canine total hip arthroplasty model without cement. J Bone Joint Surg 81-A: 93-107.

Hazzard DG, Bronson RT, McClearn GE, Strong R. (1992) Selection of an appropriate animal model to study aging processes with special emphasis on the use of rat strains $\mathbf{J}$ Gerontol: Biol Sci 47: B63-64.

Heaney RP. (1996) Nutrition and risk for osteoporosis. In: Osteoporosis. Marcus R, Feldman D, Kelsey J (eds.). Academic Press, San Diego. pp. 483-509.

Hodgen GD, Goodman AL, O’Connor A, Johnson D. (1977) Menopause in rhesus monkeys . Model for study of disorders in the human climacteric. Am J Obstet Gynecol 127: 581 - 584 .

Hornby SB, Ford SL, Timpson NJ, Ancill AK, Evans GP. (1994) Skeletal changes in the ewe after ovariectomy, J Bone Miner Res 9 (Suppl. 1): S258.

Jacobs R, Ghyselen J, Koninckx P, van Steenberghe D. (1996) Long-term bone mass evaluation of mandible and lumbar spine in a group of women receiving hormone replacement therapy. Eur J Oral Sci 104: 10-16.

Jayo MJ, Jerome CP, Lees CJ, Rankin SE, Weaver DS. (1994) Bone mass in female cynomolgus macaques: A cross-sectional and longitudinal study by age. Calcif Tissue Int 54: 231-236.

Jee WSS, Roberts WE, Park HZ, Julian G, Kramer M. (1972) Interrelated effects of glucocorticoid and parathyroid hormone upon bone remodeling. In: Calcium, Parathyroid hormone and the Calcitonins. Talmage RV, Munson PL (eds.). Excerpta Medica, Amsterdam. p. 430.

Jerome CP, Carlson CS, Register TC, Bain FT, Jayo MJ, Weaver DS, Adams MR. (1993) Bone functional changes in intact, ovariectomized, and ovariectomized, hormone-supplemented adult cynomolgus monkeys (Macaca fascicularis) evaluated by serum markers and dynamic histomorphometry. J Bone Miner Res 9: 527-540.

Johnson RB, Gilbert JA, Cooper RC, Dai X, Newton BI, 
Tracy RR, West WF, DeMoss TL, Myers PJ, Streckfus CF. (1997) Alveolar bone loss one year following ovariectomy in sheep. J Periodontol 68: 864-871.

Kalu DN. (1991) The ovariectomized rat model of postmenopausal bone loss. Bone Miner 15: 175-192.

Kaymakci B, Wark JD. (1994) Precise accurate mineral measurements of excised sheep bones using X-ray densitometry. Bone Miner 25: 231-246.

Kimmel DB. (1991) The oophorectomized beagle as an experimental model for estrogen-depletion bone loss in the adult human. Cells and Materials Suppl 1: 75-84.

Kimmel DB. (1996) Animal models for in vivo experimentation in osteoporosis research. In: Osteoporosis. Marcus R, Feldman D, Kelsey J (eds.). Academic Press, San Diego. pp. 671-690.

Lafage H-M, Balena R, Battle MA, Shea M, Seedor JG, Klein H, Hayes WC, Rodan G. (1995) Comparison of alendronate and sodium fluoride effects on cancellous and cortical bone in minipigs. J Clin Invest 95: 2127-2133.

Lo D. Animal models of disease and basic science. (1996) Horm Metab Res 28: 296-298.

Lundon K, Dumitriu M, Grynpas M. (1994) The longterm effects of ovaroectomy on the quality and quantity of cancellous bone in young macaques. Bone Miner 24: 135-149.

Mackey MS, Stevens ML, Ebert DC, Tressler DL, Combs KS, Lowry CK, Smith PN, McOsker JE. (1995) The ferret as a small animal model with BMU-based remodeling for skeletal research. Bone 17: S191-S196.

Malluche HH, Faugere M-C, Rush M, Friedler R. (1986) Osteoblastic insufficiency is responsible for maintenance of osteopenia after loss of ovarian function in experimental beagle dogs. Endocrinology 119: 2649-2654.

Mann DR, Gould KG, Collins DC. (1990) Potential primate model for bone loss resulting from medical oophorectomy or menopause. J Clin Endocr Metabol 71: 105-110.

Martin RB, Burr DB. (1989) Structure, Function and Adaption of Cortical Bone. Raven Press, New York. pp. 2430.

Martin RB, Butcher RL, Sherwood LL, Buckendhal P, Boyd RD, Farris D, Sharkey N, Dannucci G. (1987) Effects of ovariectomy in beagle dogs. Bone 8: 23-31.

Mathis JM, Petri M, Naff N. (1989) Percutaneous vertebroplasty treatment of steroid-induced osteoporotic compression fractures. Arthritis Rheum 41: 171-175.

McCubbrey DA, Yian EH, Goulet RW, Shih MS, Parfitt AM, Goldstein SA. (1993) The effects of calcitonin on trabecular bone properties in the ovariectomized beagle. Proc Orthop Res Soc, San Francisco, CA. p. 53.

Melick RA, Farrugia W, Heaton CL, Quelch KJ, Scoggins BA, Wark JD. (1988) The metabolic clearance rate of osteocalcin in sheep. Calcif Tissue Int 42: 185-190.

Melton LJ III, Kan SW, Frye MA, Wahner HW, O'Fallon WM, Riggs BL. Epidemiology of vertebral fractures in women. (1989) Am J Epidemiol 129: 1000-1011.

Miller LC, Weaver DS, McAlister JA, Koritnik DR. (1986) Effects of ovariectomy on vertebral bone in the cynomolgus monkey (Macaca fascicularis ). Calcif Tissue Int 38: 62-65.

Monier-Faugere M-C, Friedler RM, Bauss F, Malluche HH. (1993) A new bisphosphonate, BM 21.0955, prevents bone loss associated with cessation of ovarian function in experimental dogs. J Bone Miner Res 8: 1345-1355.

Monier-Faugere M-C, Geng Z, Qi Q, Arnala I, Malluche HH. (1996) Calcitonin prevents bone loss but decreases osteoblastic activity in ovariohysterectomized beagle dogs. J Bone Miner Res 11: 446-455.

Mori H, Manabe M, Kurachi Y, Nagumo M. (1997) Osseointegration of dental implants in rabbit bone with low mineral density. J Oral Maxillofac Surg. 55: 351-361.

Mosekilde L, Kragstrup J, Richards A. (1987) Compressive strength, ash weight and volume of vertebral trabecular bone in experimental fluorosis in pigs. Calcif Tissue Int 40: 318-322.

Mosekilde L, Weisbrode SE, Safron JA, Stills HF, Jankowsky ML, Ebert DC, Danielsen CC, Søgaard CH, Franks AF, Stevens ML, Paddock CL, Boyce RW. (1993a) Calcium-restricted ovariectomized Sinclair S-1 minipigs: An animal model of osteopenia and trabecular plate perforation. Bone 14: 379-382.

Mosekilde L, Weisbrode SE, Safron JA, Stills HF, Jankowsky ML, Ebert DC, Danielsen CC, Søgaard CH, Franks AF, Stevens ML, Paddock CL, Boyce RW. (1993b) Evaluation of the skeletal effects of combined mild dietary calcium restriction and ovariectomy in Sinclair S-1 minipigs: A pilot study. J Bone Miner Res 8: 1311-1321.

Motoie H, Nakamura T, O’Uchi N, Nishikawa H, Kanoh H, Abe T, Kawashima H. (1995) Effects of bisphosphnate YM175 on bone mineral density, strength, structure, and turnover in ovariectomized beagles on concomitant dietary calcium restriction. J Bone Miner Res 10: 910-920.

Müller R, Van Campenhout H, Van Damme B, Van der Perre G, Dequeker J, Hildebrand T, Rüegsegger P (1998) Morphometric analysis of human bone biopsies: A quantitative structural comparison of histological sections and micro-computed tomography. Bone 23: 59-66.

Newman E, Turner AS, Wark JD. (1995) The potential of sheep for the study of osteopenia: Current status and comparison with other animal models. Bone 16(4S): 277S284S.

O’Brien CA, Jilka RL, Manolagas SC (1997) Generation of mice harboring an IL-6 promoter-luciferase transgene that mimics endogenous IL-6 gene regulation. J Bone Miner Res 12: S435.

O’Connell SL, Tresham J, Fortune CL, Farrugia W, McDougall JG, Scoggins BA, Wark JD. (1993) Effects of prednisolone and deflazacort on osteocalcin metabolism in sheep. Calcif Tissue Int 53:117-121.

O'Connell SL (1999) The Sheep as an Experimental Model for Osteoporosis. Doctoral Thesis, Department of Medicine, The University of Melbourne, Australia.

Okamoto Y, Takahashi K, Toriyama K, Takeda N, Kitagawa K Hosokawa M, Takeda T. (1995) Femoral peak bone mass and osteoclast number in an animal model of age-related spontaneous osteopenia. Anat Rec 242: 2128.

Paganini-Hill A. (1995) The risks and benefits of estrogen replacement therapy: Leisure World. Int J Fertil 40: $54-62$.

Pastoureau P, Arlot ME, Caulin F, Barier JP, Meunier PJ, Delmas PD. (1989) Effects of oophorectomy on biochemical and histological indices of bone turnover in ewes. $\mathrm{J}$ 
Bone Min Res 4(suppl. 1): abstract 477.

Pastoureau P, Merle B, Delmas PD. (1988) Specific radioimmunoassay for ovine gla-protein (osteocalcin). Acta Endocrinologica (Copenh) 119: 152-160.

Pastoureau P, Meunier PJ, Delmas PD. (1991) Serum osteocalcin (bone gla-protein) an index of bone growth in lambs, comparison with age-related histomorphometric changes. Bone 12: 143-149.

Peng Z, Tuukkanen J, Zhang H, Jämsä T, Väänänen HK. (1994) The mechanical strength of bone in different rat models of experimental osteoporosis. Bone 15: 523-532.

Peng Z-Q, Väänänen HK, Zhang HX, Tuukkanen J. (1997) Long-term effects of ovariectomy on the mechanical properties and chemical composition of rat bone. Bone 20: 207-212.

Peter CP, Guy J, Shea M, Bagdon W, Kline WF, Hayes WC. (1996) Long-term safety of the aminobisphosphonate alendronate in adult dogs. 1 General safety and biomechanical properties of bone. J Pharmacol Exp Ther 276: 271-276.

Ricci TA, Heymsfield SB, Pierson RN, Stahl T, Chowdhury HA, Shapses SA. (2001) Moderate energy restriction increases bone resorption in obese postmenopausal women. Am J Clin Nutr 73: 347-352.

Rodgers JB, Monier-Faugere M-C, Malluche H. (1993) Animal models for the study of bone loss after cessation of ovarian function. Bone 14: 369-377.

Rosen CJ, Morrison A, Zhou H, Storm D, Hunter SJ, Musgrave K, Chen T, Wei W, Holick MF (1994) Elderly women in northern New England exhibit seasonal changes in bone mineral density and calciotropic hormones. Bone Miner 25: 83-92.

Rubin C, Turner AS, Mallinckrodt C, Fritton J, McLeod K (1997). Site-specific increase in bone density stimulated non-invasively by extremely low magnitude thirty Hertz mechanical stimulation. Proc Orthop Res Soc, San Francisco, CA. p. 110.

Rüegsegger P, Koller B, Müller R. (1996) A microtomographic system for the nondestructive evaluation of bone architecture. Calcif Tisss Int 58: 24-29.

Schildhauer, TA, Bennett AP, Wright, TM, Lane, JM, O'Leary PF. (1999) Intravertebral body reconstruction with an injectable in-situ carbonated apatite: biomechanical evaluation of a minimally invasive technique. J Orthop Res 17: $67-72$

Schreurs BW, Huiskes R, Buma P, Sloof TJJH. (1996) Biomechanical and histological evaluation of a hydroxyapatite-coated titanium femoral stem fixed with an intramedullary morsellized bone grafting technique: an animal experiment on goats. Biomaterials 17: 1177-1186.

Seebeck J, Morlock MM, Schneider E. (2000) Optimal implant anchorage in osteoporotic bone using unicortical screws. Proc Orthop Res Soc, Orlando, FL. p. 879.

Seeman E. (1996) The effects of tobacco and alcohol use on bone. In: Osteoporosis. Marcus R, Feldman D, Kelsey J (eds.). Academic Press, San Diego. pp. 577-597.

Shaw JA, Wilson SC, Bruno A, Paul EM. (1994) Comparison of primate and canine models for bone ingrowth experimentation, with reference to the effect of ovarian function on bone ingrowth potential. J Orthop Res 12: 268-273.

Shen V, Dempster DW, Birchman R, Mellish RWE,
Church E, Kohn D, Lindsay R. (1992) Lack of changes in histomorphometric, bone mass, and biochemical parameters in ovariohysterectomized dogs. Bone 13: 311-316.

Sietsma, WK. (1995) Animal models of cortical porosity Bone 17: S297-S305.

Slemenda CW, Christian JC, Reed T, Reister TK, Williams CJ, Johnston CC. (1992) Long-term bone loss in men: Effects of genetic and environmental factors. Ann Intern Med 117: 286-291.

Spencer GR. (1979) Animal model: Porcine lactational osteoporosis. Am J Path 95: 277-280.

Spurrell FA, Felts WJL, Baudin LV (1965) Osteon development in swine, In: Swine Biomedical Research. Bustad L, McClellan R (eds). pp. 173-192.

Stulberg BN, Watson JT, Stulberg SD, Bauer TW, Manley MT. (1991) A new model to assess tibial fixation in knee arthroplasty. Clin Orthop 263:288-302.

Sumner DR, Turner TM, Urban RM. (1999) In :Animal Models in Orthopaedic Research. An YH, Friedman RJ (eds.), CRC Press, Boca Raton Florida, 407-425.

Takagi H, Block E. (1991a) Effects of reducing dietary cation-anion balance on calcium kinetics in sheep. J Dairy Sci 74: 4225-37.

Takagi H, Block E. (1991b) Effects of various dietary cation-anion balances on response to experimentally induced hypocalcemia in sheep. J Dairy Sci 74: 4215-24.

Takagi H, Block E. (1991c) Effects of manipulating dietary cation-anion balance on macromineral balance in sheep. J Dairy Sci 74: 4202-14.

Thorndike E, Turner AS. (1998) In search of an animal model for postmenopausal diseases. Frontiers in Bioscience 3: 17-26.

Thorsen K, Kristoffersson A, Lorentzon R. (1996) The effects of brisk walking on markers of bone and calcium metabolism in postmenopausal women. Calcif Tissue Int 58: $221-225$.

Turner AS, Park RD, Aberman H.M, Villanueva AR, Nett TM, Trotter GW, Eckhoff DG. (1993) Effects of age and ovariectomy on trabecular bone of the proximal femur and iliac crest in sheep. Proc Orthop Res Soc, San Francisco, CA. p. 548.

Turner AS, Alvis M, VanderVliet MM, Wander K, Bryant HU (1994) Heterogeniety of bone mineral density in ewes. Proc Orthop Res Soc, New Orleans, LA. p. 441.

Turner AS, Alvis MR, Myers W, Lundy MW. (1995a) Changes in bone mineral density and bone-specific alkaline phosphatase in ovariectomized ewes. Bone 17(Suppl.): 395S-402S.

Turner AS, Alvis MR, Mallinckrodt CH, Bryant HU. (1995b) Dose-response effects of estradiol on bone mineral density in ovariectomized ewes. Bone 17(Suppl.): 421S$427 \mathrm{~S}$.

Turner AS, Eckhoff DG, Alvis MR, Villanueva AR, Aberman HM. (1996a) Failure of hydroxylapatite coating to promote biologic fixation in an estrogen-deficient model. Proc Orthop Res Soc, Atlanta, GA. p. 155.

Turner AS, Edgerton M, Alvis M, Bryant HU. (1996b) Mandibular bone density in the ovariectomized ewe. Proc 7 th International Congress of Bone Morphometry, Alghero, Sardinia, Italy. Bone 19 (Supplement) 164S (Abstr.).

Turner AS, Villanueva AR, Eckhoff DG, Alvis MR, 
Aberman HM (1996c) Estrogen and bone ingrowth into implants. Proc Interface of Biomechanics and Cell Biology in Orthopaedics. Johns Hopkins Medical Institutions, Department of Orthopaedic Surgery. (Abstr).

Turner AS Eckhoff DG, Dewell RD, Villanueva AR, Aberman HM. (1998) Peri-apatite-coated implants improve fixation in osteopenic. Proc Orthop Res Soc, New Orleans, LA. p. 4.

Turner AS, Hannan MK, Bouxsein ML Kaufman LW, Mallinckrodt CH, Bryant HU. (1999a). Effects of raloxifene (LY139481) on bone density and bone strength in aged, ovariectomized ewes. Proc Orthop Res Soc, Anaheim, CA p. 230 .

Turner AS, Dewell RD, Kaufman LW, Mallinckrodt CH, Bryant HU. (1999b) Raloxifene (LY 139481) increases bone mineral density of the mandible in aged ovariectomized ewes. Proc $8^{\text {th }}$ World Congress of the International Society of Orthopaedic Research and Traumatology, Sydney. (Abstract).

Vanderschueren D, Van Herck E, Suiker AMH, Allewaert K, Visser WJ, Geusens P, Bouillon R. (1992) Bone and mineral metabolism in the adult guinea pig : Long-term effects of estrogen and androgen deficiency. J Bone Miner Res 7: 1407-1415.

Van Heest A, Swionkowski M. (1999) Bone-graft substitutes Lancet 353 (Suppl 1): 28-29.

Vanin CM, MacLusky NJ, Chachra D, Kasra M, Grynpas
MD, Casper RF. (1995) Lumbar vertebral density and mechanical properties in aged ovariectomized rats treated with estrogen and norethindrone or norgestimate. Am J Obstet Gynecol 173: 1491-1498.

Vidovszky TJ, Bronk JT, Witkiewicz H, Meyer WA, Turner RT, Ilstrup DM, An K-N, Rock MG, Morrey BF, Bolander ME.(1996) Accelerated production of UHMWPE debris in the sheep: A possible model for bone loss around femoral stems. Proc Orthop Res Soc, Atlanta, GA p. 274.

Weiss RA (1998) Retrovial zoonoses. Nature Med 4:391392.

Wronski TJ, Lowry PL, Walsh CC, Ignaszewski LA. (1985) Skeletal alterations in ovariectomized rats. Calcif Tissue Int 37: 324-328.

Wronski TJ, Walsh CC, Ignaszewski LA. (1986) Histologic evidence for osteopenia and increased bone turnover in ovariectomized rats. Bone 7: 119-123.

Wronski TJ, Yen C-F. (1991) The ovariectomized rat as an animal model for postmenopausal bone loss. Cells and Materials Suppl 1: 69-74.

Yamaura, M, Nakamura T, Nagai Y, Yoshihara A, Suzuki K. (1993) Reduced mechanical competance of bone by ovariectomy and its preservation with 24R, 25dihydroxyvitamin D3 administration in beagles. Calcif Tissue Int 52: 49-56. 